\title{
Deposition and stability of metal ions on oxidised silicon surfaces: electrochemical correlation
}

\author{
Sefik Süzer* \\ Bilkent University, Chemistry Department, 06533 Ankara, Turkey
}

Received 8 August 2000; received in revised form 21 September 2000; accepted 3 October 2000

\begin{abstract}
XPS is used to determine the chemical state of $\mathrm{Au}, \mathrm{Hg}, \mathrm{Tl}, \mathrm{Pb}$ and $\mathrm{Bi}$ deposited from their corresponding aqueous solutions on oxidized silicon or gold surfaces. It is determined that $\mathrm{Au}$ and $\mathrm{Hg}$, having positive electrochemical reduction potentials, deposit in their 0-valent state, but $\mathrm{Tl}, \mathrm{Pb}$ and $\mathrm{Bi}$, having small positive or negative electrochemical reduction potentials, deposit in their corresponding ionic states, confirming our previous hypothesis about the electrochemical correlation. Electrochemical deposition of Au from aqueous solutions on to silicon electrodes yields 0 -valent Au on both $(+)$ and (-) polarised electrodes, with the only difference that more gold is deposited on the negatively biased one. (C) 2001 Elsevier Science B.V. All rights reserved.
\end{abstract}

Keywords: XPS; Chemical states of $\mathrm{Au} ; \mathrm{Hg} ; \mathrm{Tl} ; \mathrm{Pb} ; \mathrm{Bi}$; Reduction potentials

\section{Introduction}

Electrochemical, chemical (electroless), and physical (vapour) deposition of metals and/or their salts onto various surfaces have always been important in fields involving semiconductors, coatings, catalysis, solar energy applications, etc. Through the important developments in nanoscience/nanotechnology, there has been a renewed interest in understanding and/or control of these deposition processes. Numerous researchers have been able to manipulate the deposition of metals in nanometer dimensions on silicon surfaces using scanning tunnelling techniques [1-4]. Fundamental questions governing these processes

\footnotetext{
*Present address: Brookhaven National Laboratory, NSLS Building, 725A/U8b, Upton, NY 11973-5000, USA.

E-mail address: suzer@fen.bilkent.edu.tr (S. Süzer).
}

and related chemical and/or electrochemical properties of the metal ions and the corresponding substrates are still subject of some debate. Electroless and reductive deposition of $\mathrm{Pd}, \mathrm{Ag}, \mathrm{Pt}, \mathrm{Au}$ and $\mathrm{Cu}$ from aqueous solutions of their corresponding ions on porous silicon have been reported [5-8]. In one of our recent study, we also reported on deposition of gold from an aqueous solution of $\mathrm{AuCl}_{3}$ on to oxidised silicon surfaces with various oxide thicknesses. We claimed that the large and positive electrochemical reduction potential of $\mathrm{Au}^{3+}$ ion was the determining factor for the reductive deposition of $\mathrm{Au}^{3+}$ onto the surface [9]. Earlier, we also had reported similar electrochemical correlation during XPS investigation of some metal ions deposited on the surface of silica tubes for atom-trapping atomic absorption spectrometric determinations $[10,11]$. In this contribution, we extend our study to deposition 
of $\mathrm{Au}, \mathrm{Hg}, \mathrm{Tl}, \mathrm{Pb}$ and $\mathrm{Bi}$ ions from their corresponding aqueous salts on oxidised silicon or gold surfaces to further test the electrochemical correlation. These metals are chosen since both they follow one another in the periodic table, yet they represent a wide-enough range of electrochemical reduction potentials $(-0.3$ to $+1.5 \mathrm{~V})$ to test our hypothesis.

\section{Experimental}

$\mathrm{Si}$ wafers with their polished surfaces and/or a strip of gold were used for deposition of dilute ca. $10^{-4} \mathrm{M}$ aqueous solutions of $\mathrm{AuCl}_{3}, \mathrm{HgCl}_{2}, \mathrm{Tl}_{2} \mathrm{SO}_{4}$, $\mathrm{Pb}\left(\mathrm{NO}_{3}\right)_{2}$ and $\mathrm{Bi}\left(\mathrm{NO}_{3}\right)_{3}$. Si wafers were cleaned by $10 \%$ HF before thermal treatment or metal deposition. Different oxide thicknesses $(1-10 \mathrm{~nm})$ were obtained by heating the substrate in air at different temperatures or for different periods. The substrates then were immersed into the solution for $10 \mathrm{~h}$ without stirring after which they were washed with acetone, dried in air, and immersed into the spectrometer. For electrochemical deposition, two silicon wafers of the same dimension were used as electrodes. One of the electrodes was used as cathode and the other as anode. They were placed into the corresponding solution and electrolysed for a period of ca. $30 \mathrm{~min}$ with a total current of less than $5 \mathrm{~mA}$. A Kratos ES300 electron spectrometer with unmonochromatised $\mathrm{MgK} \alpha \mathrm{X}$-rays was used for XPS analysis. The power of the anode was kept at a minimum level $(15 \mathrm{kV}, 8 \mathrm{~mA}$, power density ca. 120 Watt/ $\mathrm{cm}^{2}$ ) to avoid the well-known X-ray induced reduction of the metal ions [12-16].

\section{Results and discussions}

\section{1. $\mathrm{Au}^{3+}$ deposition $\mathrm{on}_{\mathrm{SiO}} / \mathrm{Si}$}

Fig. 1 displays the XPS spectra of Si2p and Au4f regions of gold deposited on to silicon surfaces containing approximately 3,5 and $10 \mathrm{~nm}$ oxide layers. Binding energy of the $\mathrm{Au} 4 \mathrm{f}_{7 / 2}$ peak is determined as $84.4 \mathrm{eV}$ by referencing it to the $\mathrm{Si} 2 \mathrm{p}$ peak of the bulk $\mathrm{Si}^{0}$ which is taken as $99.5 \mathrm{eV}$ [15]. Since the $4 f_{7 / 2}$ binding energy of the metallic gold is $84.0 \mathrm{eV}$ and binding energy shift of up to $1 \mathrm{eV}$ is

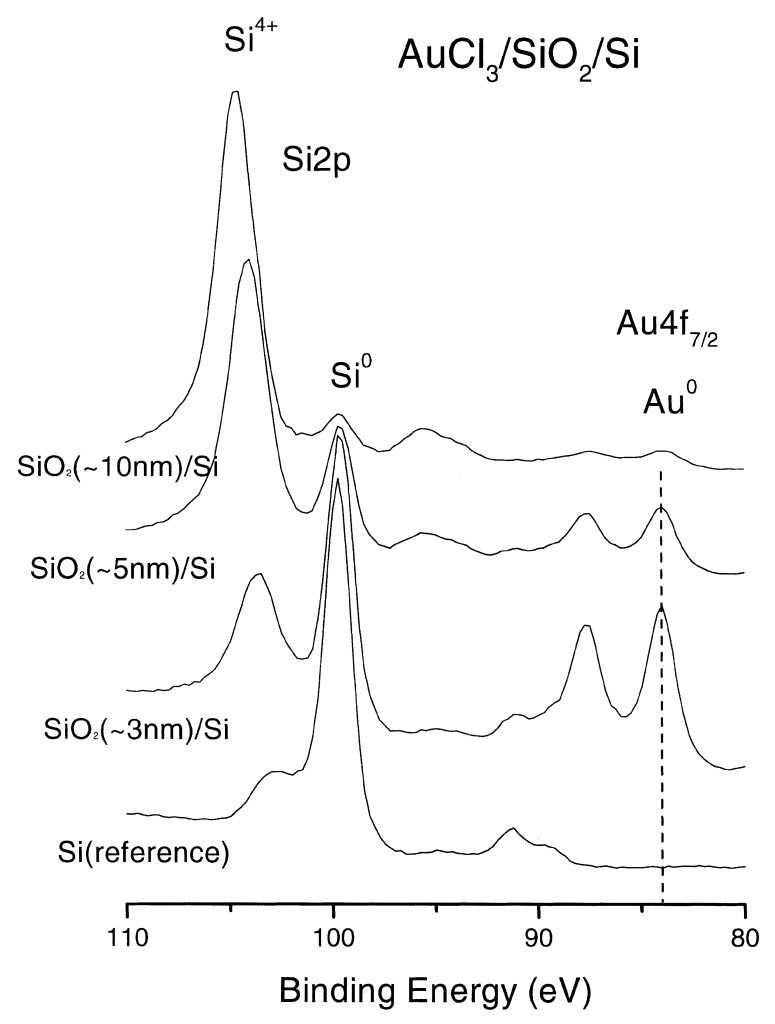

Fig. 1. Part of the XPS spectra of $\mathrm{HAuCl}_{4}$ (aq.) deposited on silicon substrates containing different oxide thicknesses.

frequently observed for different substrates, the chemical state of gold is assigned to be 0 [10-15]. Hence, in all the various $\mathrm{SiO}_{2} / \mathrm{Si}$ substrates, gold is determined to have deposited in its 0 -valent state and there is an inverse correlation between the quantity of gold deposited with the thickness of the oxide layer. By decreasing the electron take-off angle to lower values, it was also determined that $\mathrm{Au}$ was deposited on top of the oxide layer and in the form of colloidal particles of varying sizes of less than 100 $\mathrm{nm}$ (using S.E.M.). Similar analysis of gold deposited on metal ( $\mathrm{Pt})$, quartz, and polypropylene substrates yielded similar results that from a dilute aqueous solution, gold, having a large and positive electrochemical reduction potential $(+1.5 \mathrm{~V})$, always deposits in its 0 -valent state $[9-11,15]$. The electrochemically deposited gold is also in its 0 -valent state both for (+) and (-) biased silicon electrodes as shown in Fig. 2. The only difference is that more gold is deposited on the negatively biased one. 


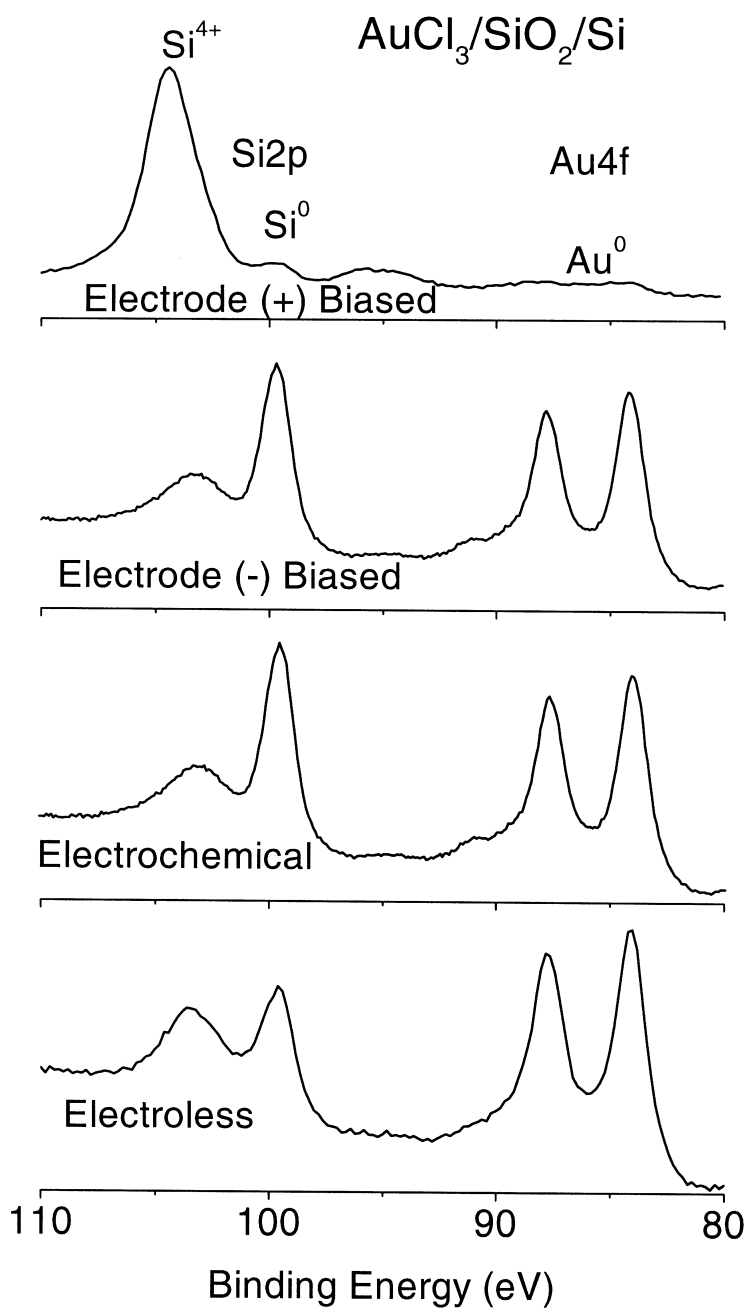

Fig. 2. Part of the XPS spectra of of $\mathrm{HAuCl}_{4}$ (aq.) deposited on silicon substrate using both electrochemical and electroless techniques.

\section{2. $\mathrm{Au}, \mathrm{Hg}, \mathrm{Tl}, \mathrm{Pb}$ and $\mathrm{Bi}$ deposition $\mathrm{On} \mathrm{SiO}_{2} / \mathrm{Si}$} and or $\mathrm{Au}$

Fig. 3 shows the collected spectra of the metals investigated. The binding energies of $\mathrm{Si} 2 \mathrm{p}$ and $\mathrm{Hg}$ 4f and Si 2s and Bi $4 \mathrm{f}$ overlap, hence, although their spectra are recorded and analysed on both silicon and gold substrates, only the spectra on gold are reproduced in the figure. The relevant data is given in Table 1. Assignments of the chemical states in Au, $\mathrm{Hg}, \mathrm{Pb}$ and $\mathrm{Bi}$ are straightforward since there is approximately $2 \mathrm{eV}$ binding energy difference be-

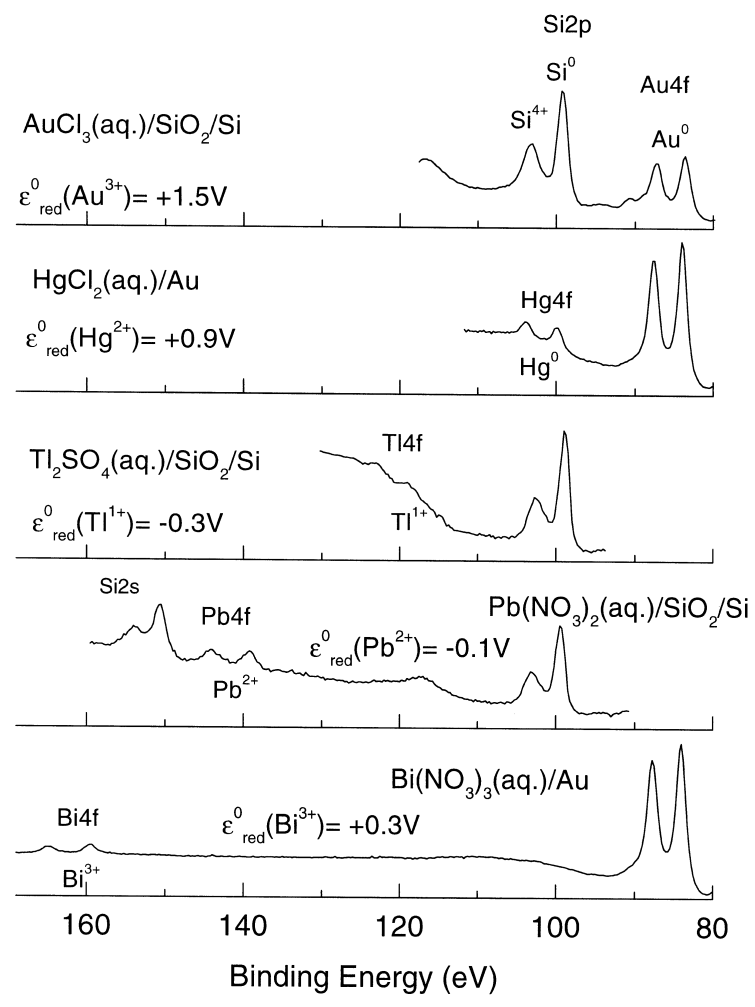

Fig. 3. Part of the XPS spectra of $\mathrm{Au}, \mathrm{Hg}, \mathrm{Tl}, \mathrm{Pb}$ and $\mathrm{Bi}$ deposited on silicon or gold substrates.

Table 1

Measured and tabulated binding energies the $4 \mathrm{f}_{7 / 2}$ levels of $\mathrm{Au}$, $\mathrm{Hg}, \mathrm{Tl}, \mathrm{Pb}$ and $\mathrm{Bi}$ deposited on silicon and/or gold substrates

\begin{tabular}{lllll}
\hline & \multicolumn{3}{l}{ B.E. $4 f_{7 / 2}(\mathrm{eV})^{\mathrm{a}}$} \\
\cline { 2 - 5 } & $\mathrm{SiO}_{2} / \mathrm{Si}^{\mathrm{b}}$ & $\mathrm{Gold}^{\mathrm{c}}$ & Ref. [15] & Others Refs. [11,12] \\
\hline $\mathrm{Au}^{0}$ & \multicolumn{1}{l}{84.4} & & 84.0 & 84.7 \\
$\mathrm{Au}^{3+}$ & - & & 86.7 & 87.4 \\
$\mathrm{Hg}^{0}$ & 100.2 & 99.9 & 99.9 & \\
$\mathrm{Hg}^{2+}$ & - & - & & \\
$\mathrm{Tl}^{0}$ & - & & 117.7 & \\
$\mathrm{Tl}^{1+}$ & 119.4 & & 117.7 & \\
$\mathrm{~Pb}^{0}$ & - & & 136.9 & \\
$\mathrm{~Pb}^{2+}$ & 139.3 & & 138.9 & \\
$\mathrm{Bi}^{0}$ & - & - & 156.9 & 156.9 \\
$\mathrm{Bi}^{3+}$ & 159.9 & 159.7 & 159.9 & 160.0 \\
\hline
\end{tabular}

${ }^{\mathrm{a}}$ Uncertainty in binding energies is estimated to be $0.2 \mathrm{eV}$.

${ }^{\mathrm{b}}$ Referencing was done with respect to $\mathrm{Si} 2 \mathrm{p}$ by assigning 99.5 $\mathrm{eV}$ to the $\mathrm{Si}^{0}$ peak.

${ }^{\mathrm{c}}$ Referencing was done with respect to $\mathrm{Au} 4 \mathrm{f}_{7 / 2}$ assigning 84.0 to the $\mathrm{Au}^{0}$ peak.

${ }^{\mathrm{d}}$ Binding energies may shift up to $1 \mathrm{eV}$ depending on the substrate $(9,11)$. 
tween their corresponding ionic and 0-valent states [15]. For $\mathrm{Tl}$ the $4 \mathrm{f}_{7 / 2}$ binding energies for both ionic and 0-valent states are given as $117.7 \mathrm{eV}$. Our measured value (119.4) is $1.7 \mathrm{eV}$ larger, too large to attribute to any substrate shift. Hence, we assign the chemical state of $\mathrm{Tl}$ as $1+$.

Deposition from aqueous solutions and/or from the vapor phase onto surfaces is a complex chemical and/or electrochemical process, which involves participation of both active sites on the surfaces and the species depositing. In the light of our findings, we can postulate that $\mathrm{Au}$ and $\mathrm{Hg}$, having positive electrochemical reduction potentials $(+1.5$ and +0.9 $\mathrm{V}$, respectively), deposit in their 0 -valent state. $\mathrm{Tl}, \mathrm{Pb}$ and $\mathrm{Bi}$, having small positive or negative electrochemical reduction potentials $(-0.3,-0.1$ and +0.3 $\mathrm{V}$, respectively), deposit in their corresponding ionic states. These five metal ions (consecutive in the periodic table) seem to confirm our hypothesis on the correlation of deposition with their electrochemical reduction potentials.

Obviously, other species must be oxidised (either on the surface or in the solution) if the metals are reductively deposited from their solutions. $\mathrm{Si}-\mathrm{H}$ or other active surface sites are likely candidates, however, further work is needed to clarify these points, the mechanism and role of the substrate.

\section{References}

[1] R. Srinnivisan, I.I. Suni, Surf. Sci. 408 (1988) L698.

[2] H. Sugimura, N. Nakagiri, Appl. Phys. Lett. 66 (1995) 1430.

[3] H. Sugimura, N. Nakagiri, J. Vac. Sci. Technol. B 13 (1995) 1933.

[4] G. Gorostiza, J. Servat, J.R. Morante, F. Sanz, Thin Solid Films 275 (1996) 12.

[5] D. Andsager, J. Hilliard, M.H. Nayfeh, Appl. Phys. Lett. 64 (1994) 1141.

[6] T.K. Sham, I. Coulthard, J.W. Lorimer, A. Hiraya, M. Watanabe, Chem. Mater. 6 (1994) 2085.

[7] I. Coulthard, T.K. Sham, Mater. Res. Soc. Symp. Proc. 452 (1997) 547.

[8] I. Coulthard, S. Degen, Y.J. Zhu, T.K. Sham, Can. J. Chem. 76 (1998) 1707.

[9] S. Suzer, O. Dag, Can. J. Chem. 78 (2000) 516.

[10] S. Suzer, N. Ertas, S. Kumser, O.Y. Ataman, Appl. Spectrosc. 51 (1997) 1537.

[11] S. Suzer, N. Ertas, O.Y. Ataman, Appl. Spectrosc. 53 (1999) 479.

[12] R.G. Copperthwaite, Surf. Interface Anal. 2 (1980) 17.

[13] J.B. Malherbe, S. Hofmann, J.M. Sanz, Appl. Surf. Sci. 27 (1986) 355.

[14] D.F. Mitchell, G.I. Sproule, M.J. Graham, Surf. Interface Anal. 15 (1990) 487.

[15] D. Briggs, M.P. Seah, 2nd Edition, Practical Surface Analysis, Vol. 1, Wiley, Chichester, 1996.

[16] S. Suzer, Appl. Spectrosc. 54 (2000) 1716. 